\title{
Erratum to: Curdlan-conjugated PLGA Nanoparticles possess macrophage stimulant activity and drug delivery capabilities
}

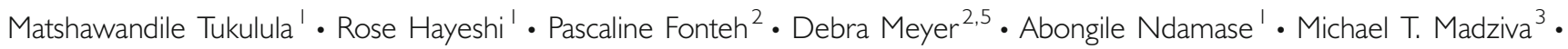

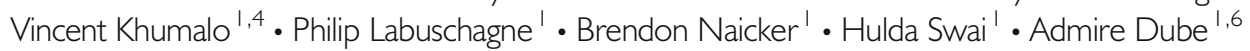

Published online: 9 June 2015

(C) Springer Science+Business Media New York 2015

\section{Erratum to: Pharm Res}

DOI I 0.1007/s I | 095-0 I 5- I 655-9

In the original version of this article, one of the authors is incorrectly listed as Philip Lubuschagne. This author's name should read Philip Labuschagne.

The online version of the original article can be found at http://dx.doi.org/l0. | 007/s | |095-0|5-|655-9.

\section{Admire Dube}

adube@uwc.ac.za

Encapsulation and Delivery Group, Council for Scientific and Industrial Research, I Meiring Naude Road, Brummeria Pretoria 000 I, South Africa

2 Department of Biochemistry, Faculty of Natural and Agricultural Sciences, University of Pretoria, Pretoria 0002, South Africa

3 School of Physiology, Faculty of Health Sciences, University of the Witwatersrand, 7 York Road, Parktown, Johannesburg 2193, South Africa

4 DST/CSIR National Centre for Nanostructured Materials, Council for Scientific and Industrial Research, I Meiring Naude Road, Brummeria Pretoria 000 I, South Africa

5 Present address: Department of Biochemistry, Faculty of Sciences University of Johannesburg, P.O Box 524, Auckland Park Johannesburg 2006, South Africa

6 Present address: Pharmaceutics Discipline, School of Pharmacy University of theWestern Cape, Bellville 7535, South Africa 